\section{Multidisciplinary Therapy of Extensive Oligodontia: A Case Report}

Thaís Marques Simek Vega Gonçalves ${ }^{1}$, Letícia Machado Gonçalves ${ }^{1}$, José Ribamar Sabino-Bezerra2 ${ }^{2}$ Alan Roger Santos-Silva², Wander José da Silva', Renata Cunha Matheus Rodrigues Garcia ${ }^{1}$

\author{
'Department of Prosthodontics and \\ Periodontology, Piracicaba Dental \\ School, UNICAMP - University of \\ Campinas, Piracicaba, SP, Brazil \\ ${ }^{2}$ Department of Oral Diagnosis, \\ Piracicaba Dental School, \\ UNICAMP - University of \\ Campinas, Piracicaba, SP, Brazil
}

Correspondence: Profa. Dra. Renata Cunha Matheus Rodrigues Garcia, Avenida Limeira, 901, 13414-903 Piracicaba, SP, Brasil. Tel:+55-19-2106-5240. e-mail: regarcia@fop.unicamp.br

Key Words: oligodontia, temporary partial denture, case report.

\section{Introduction}

Oligodontia is considered a rare condition that consists in the congenital absence of six or more teeth, excluding the third molars (1-3). The loss of several permanent teeth causes masticatory impairment with long-term problems, including a negative impact on the remaining teeth. Previous studies have reported a prevalence of around $0.1 \%$ to $0.3 \%$ when considering the worldwide population $(4,5)$, with no gender differences $(2,6)$. The etiology of oligodontia includes several hypotheses such as traumatic injury during tooth development, endocrine disturbances, infections, as well as radiation or chemotherapy during childhood cancer therapy $(4,7)$. Moreover, specific genes have been associated with tooth agenesis, particularly the MSX1 (8), PAX9 (9) and AXIN2 mutations (10).

This condition is mostly manifested in the permanent dentition $(11,12)$ and the diagnosis is normally based on radiographic evidence and routine clinical examination detecting delayed eruption of permanent teeth, which begins around 6 to 12 years of age (2). During the diagnosis process, several other dental and oral symptoms can be observed, including reduced size and form of teeth, delayed growth of the alveolar processes, deficiency of teeth eruption, persistent deciduous teeth, taurodontism, false diastema, and deep overbite $(13,14)$. Speech and masticatory disorders may also occur (15). However, aesthetic and psychological problems require special attention for these patients, considering that they are often associated with low self-esteem and problems of social acceptance $(16,17)$. Thus, early diagnosis and treatment are important to encourage and improve masticatory function, speech, appearance and reduce the psychosocial impact (15).
The optimal therapy should include an interdisciplinary team approach, and rely on positive interaction between pediatric dentists, orthodontists, oral and maxillofacial surgeons and prosthodontics $(11,13,15)$. The treatment goals are to keep the remaining teeth, recover the masticatory function and aesthetics, speech improvement, and reestablish the emotional and psychological well being (7). Hence, the following case report summarizes the multidisciplinary treatment approach to a 12-yearold patient diagnosed with oligodontia, with absence of 11 permanent teeth.

\section{Case Report \\ Pre-Treatment Evaluation}

A 12-year-old male was referred to Piracicaba Dental School, State University of Campinas, Brazil, seeking a comprehensive aesthetic dental rehabilitation. A detailed clinical interview was undertaken with the patient and his legal guardian, which revealed no classical syndrome features, such as ectodermal dysplasia associated with missing teeth. The dental history included absence of dental caries and no previous treatment for the missing teeth.

The extraoral clinical examination revealed a mild reduction of the lower third of facial height, with profile changes including a marked nasolabial angle and procumbent lip contours; however, the facial symmetry was not affected. No clicking or crepitus of the temporomandibular joint was detected and masticatory muscles were not sensitive upon palpation.

During the intraoral examination, the absence of 11 permanent teeth was noted, including maxillary lateral incisors and canines, mandibular central and lateral incisors, mandibular right canine and mandibular right 
first and second premolars (Fig. 1A). The mandibular left permanent canine (conical shape), maxillary right primary canine, and mandibular right first and second primary molars were present in dental arches. Regarding the soft tissues, the labial frenulum was within normal limits, there were no soft tissue masses, swelling or lesions present on the gingival, buccal and labial mucosa, tongue or alveolar mucosa. Oral hygiene was considered satisfactory and no bleeding on probing of the periodontal tissues was noted. The patient also presented upper midline diastema and underdeveloped alveolar ridges in the anterior mandibular region. In addition, a parafunctional habit of thumbsucking during sleep was self-reported by the patient, and clinically confirmed by the presence of an anterior open bite and tongue interposition during speech. Moreover, the patient reported extreme difficulty in chewing and severe aesthetic dissatisfaction, which resulted in several social problems.

Panoramic radiograph examination showed no osseous lesions and a dense alveolar bone (Fig. 1B). The images of retained primary teeth revealed severe root resorption and absence of permanent successors. Cephalometric analysis revealed a regular development of the cranial base with a counterclockwise rotational pattern of the maxilla. The facial pattern was classified as mesofacial with a reduction of lower anterior face height (Ricketts analysis). Lateral radiograph showed a Class I skeletal pattern with a normal growth pattern.

After careful clinical interview, clinical examination, radiographic and cephalometric analysis, a diagnosis of oligodontia was confirmed and a multidisciplinary treatment approach was planned.

\section{Treatment Planning}

The treatment plan comprised 2 phases. Prior to any clinical procedure, all primary teeth were scheduled for extraction due to poor crown-to-root ratio. After extractions and before orthodontic treatment, a mandibular removable denture was inserted and used during the whole orthodontic treatment period in order to provide an immediate aesthetic benefit. A pre-prosthetic orthodontic treatment was conducted only in the maxilla, aiming to reestablish the space between the incisors and premolars in order to properly replace the missing teeth. Further, the patient underwent correction of the overbite and anterior open bite while improving incisal relation and lip support. Simultaneously to orthodontics, speech therapy was performed in order to improve tongue position during speech. After orthodontic treatment and speech therapy, the second-phase plan was accomplished, consisting of prosthetic treatment aimed to provide masticatory function and improved aesthetics.
Phase I - Orthodontic Treatment and Speech Therapy

Orthodontic treatment was performed only in the maxilla due to the small number of mandibular teeth. Orthodontic bands were used on molars and brackets (0.022" slot, Roth prescription) were applied on the remaining permanent teeth. Furthermore, artificial maxillary lateral and canine teeth were incorporated into the orthodontic appliance in order to maintain aesthetics. Afterwards, 0.018", 0.017" x 0.025" NiTi arch wires were used sequentially allowing the adjustment of the position and angle of the permanent teeth. The maxillary midline diastema was closed with elastic chains and a needed maxillary lateral incisor space was provided. Lip position was also improved. The teeth alignment was completed by using $0.019 " \times 0.025^{\prime \prime} \mathrm{NiTi}$ arch wire and total orthodontic treatment was completed after 8 months.

Throughout the process, speech therapy was performed in order to eliminate the parafunctional habit and improve word pronunciation. Vocal and articular exercises were accomplished to improve tongue position during speech. After both orthodontic and speech treatments (Fig. 1C), the prosthetic phase started.

\section{Phase II - Prosthetic Treatment}

Considering that the craniofacial growing of a 12-yearold patient is not complete, temporary maxillary and mandibular removable partial dentures were determined to be the treatment of choice. The conical mandibular right canine was reshaped with composite, and diagnostic casts were fabricated using irreversible hydrocolloid (Jeltrate; Dentsply Ind. e Com. Ltda., Petrópolis, RJ, Brazil), and poured in Type III dental stone (Herodent; Vigodent, Rio de Janeiro, RJ, Brazil). Custom trays were then fabricated using autopolymerized acrylic resin (Clássico Artigos Odontológicos Ltda., São Paulo, SP, Brazil), and definite impressions of the maxillary and mandibular dental arches were obtained with silicone (Xantopren; Heraeus Kulzer, São Paulo, SP, Brazil). Next, working casts were obtained and the maxillary cast was mounted on a semi-adjustable articulator, using a face ball (Gnatus 8600; Gnatus, Ribeirão Preto, SP, Brazil). The interocclusal relationship in the maximum intercuspal position was clinically determined using vinylpolysiloxane, and the mandibular cast was then mounted on the articulator. The artificial teeth were arranged in wax for clinical trial evaluation.

The occlusion and position of the artificial teeth were clinically evaluated and the necessary corrections were made before denture processing. The maxillary denture was planned with a containment arc on permanent incisors and artificial teeth in order to maintain the dental position obtained by the orthodontic treatment, and mimic the use of removable dentures, similar to a removable orthodontic 
appliance. Finally, the temporary dentures were inserted (Fig. 1D, 1E, and 1F) and the patient was instructed to use them continuously in order to retain the orthodontic treatment result until the age of skeletal maturity, when definitive prosthodontic treatments could be planned.

Written and verbal instructions on how to use, to clean and maintain the prostheses were given to the child and his parents, and the patient was instructed to return the following day and once a week for two months for inspection and possible corrections and adjustments.

The patient has familiarized himself with the dentures in a short time and showed considerable speech and masticatory function improvement. Additionally, it was reported that his self-esteem and quality of life improved remarkably.

\section{Discussion}

Several factors are involved in the complex treatment planning for patients with oligodontia, especially when a large number of teeth are missing, presenting the greatest challenge to the interdisciplinary team $(11,13,15)$. The lack of 11 teeth leads to a severe limitation on aesthetics and mastication and these effects could become crucial as the child reaches school age when social relationships are established. Thus, a multidisciplinary approach was planned, including orthodontics, speech therapy and prosthodontics,
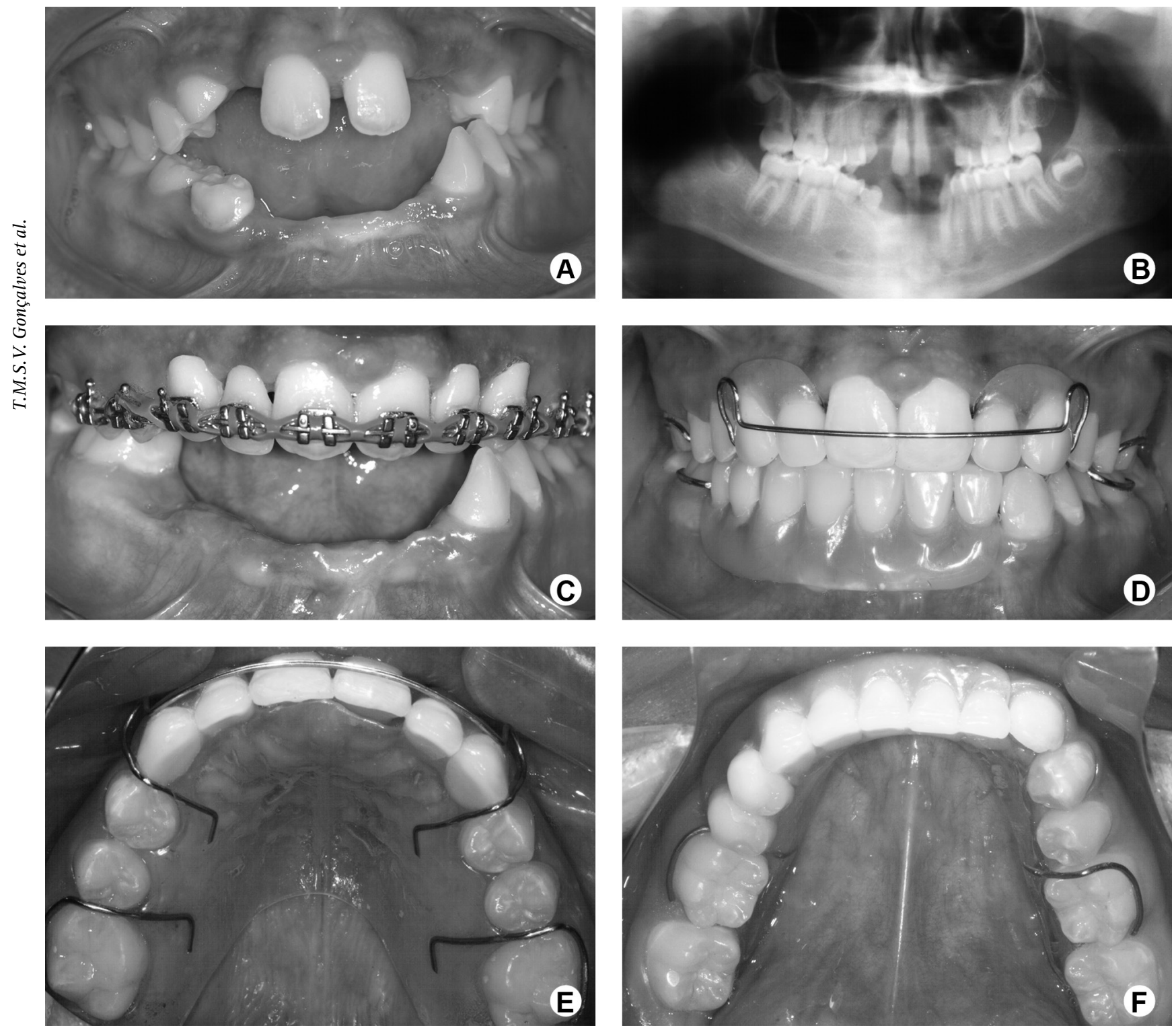

Figure 1. Composite figure of photographs and radiographs of the case. A: Pretreatment frontal view showing excessive open bite and diastema in the anterior teeth. B: Pretreatment panoramic radiograph shows hypodontia and lack of teeth development. C: Post-orthodontic frontal view of dentition showing maxillary incisors alignment and reduced open bite. D: Frontal view of the final removable partial dentures in position. E: Occlusal view of the maxillary removable partial denture in position. F: Occlusal view of the mandibular removable partial denture in position. 
to ensure adequate and durable results.

The orthodontic treatment was of fundamental importance to reestablish the correct position of the remaining teeth. However, the orthodontic appliance was used only on the maxilla due to the large amount of missing teeth in the mandible. The main goals were to reduce the overjet, correct the open bite, and close the midline diastema, besides prevent the existing teeth from settling in abnormal positions and deflect. These procedures restored the teeth position, assisting the processing of the proper removable dentures. In addition, the braces combined with artificial teeth allowed the immediate restoration of the anterior missing teeth, improving aesthetic and patient self-esteem. On the other hand, the orthodontic treatment alone would not be successful, since patient had speaking problems due to tongue interposition during speech and thumb sucking during sleep. Thus, the simultaneous vocal and articular speech exercises were crucial for treatment results and improved tongue position besides reducing the thumb-sucking habit.

Regarding the prosthetic treatment, its objectives included 1) restore the masticatory function, 2) maintain the position of adjacent natural teeth preventing undesirable movements, such as inclination, extrusion or migration, 3) improve aesthetics, 4) avoid social problems to the patient, especially in adolescence, 5) replace the missing teeth without interfering on the growth of mandible and maxilla. In the prosthetic area, it is not important only the number of missing teeth, but also their distribution on the dental arch, which is a critical factor in the estimated treatment needs. Patients presenting a small number of missing teeth can be treated by adhesive restoration, fixed prosthesis, and dental implants. However, for patients with a large number of missing teeth, as the child of the present case, the treatment choices should include overdentures supported by natural teeth or by osseointegrated implants, fixed prostheses, or temporary/definitive removable partial dentures (12). However, the age of the patient of the present case was carefully considered, since younger adults require special attention with regard to their psychological and emotional condition, and particularly the anatomical changes related to facial growth. In the last context, the installation of implants is contraindicated and should be postponed until after puberty or after the growth spurt of the child (16-18). It must also be pointed out that the development of jaws could be limited when implants are used (12), especially when the implants are fixed together in a prosthesis with multiple elements. Moreover, implants placed in young patients act as ankylosed teeth resulting in infraocclusion of the restoration $(19,20)$. Another reason for implant contraindication is related to the atrophy of the ridge, a common condition in oligodontia patients, and that interferes with the longevity of implants $(20,21)$. As a result of all these facts, the placement of implants in the growing maxilla should be avoided until early adulthood (21).

Another prosthetic treatment option that could have been considered for this clinical case is the conventional fixed prosthesis. However, this type of prosthesis imposes tooth structure removal, which can lead to pulp exposure in young patients. The potential for jaw growth also contraindicates the use of this prosthesis (22), as jaw growth can lead to altered occlusion and poor aesthetics. Additionally, the possible presence of conical teeth is not propitious to retentive crown preparation (12).

Considering all possibilities for oral rehabilitation of the referred patient, the prosthetic treatment of choice was the placement of temporary removable partial dentures. This type of prosthesis allows the restoration of function and aesthetics of missing teeth, and does not interfere with bone development and eruption of permanent teeth. Thus, the multidisciplinary treatment allowed the patient to achieve greater self-esteem and better social acceptance, and provided reestablishment of masticatory function and aesthetics until the final treatment plan could be performed after bone growth.

The multidisciplinary clinical approach comprehending orthodontics, speech therapy and prosthodontics was mandatory for this patient with oligodontia because it could restore function and aesthetics in the best possible manner for the characteristics of the case, aiding the child to achieve social and emotional maturity.

\section{Resumo}

A oligodontia é uma doença rara, congênita, caracterizada pela ausência de seis ou mais dentes. Este relato de caso descreve uma abordagem terapêutica multidisciplinar de um adolescente de 12 anos de idade com ausência de 11 dentes permanentes. Antes de qualquer procedimento, todos os dentes decíduos foram extraidos devido à pobre relação coroaraiz. 0 plano de tratamento foi constituído por duas fases: 1. terapia ortodôntica e fonoaudiológica com o objetivo de ajuste de sobre-mordida e mordida aberta anterior, bem como melhoria da posição da língua, e 2. tratamento reabilitador protético através da instalação de próteses parciais removiveis provisórias. A abordagem multidisciplinar envolvendo os tratamentos ortodônticos, fonoaudiológico e protético reestabeleceram a função mastigatória e a estética, melhorando a autoestima e aceitação social do paciente.

\section{Acknowledgments}

The authors gratefully acknowledge Dr. Maria Antonieta Marques Simek Vega for her assistance with the orthodontic treatment.

\section{References}

1. Dhanrajani PJ. Hypodontia: etiology, clinical features, and management. Quintessence Int 2002;33:294-302.

2. Schalk-van der Weide $Y$, Beemer FA, Faber JA, Bosman F. Symptomatology of patients with oligodontia. J Oral Rehabil 1994;21:247-261.

3. Kulkarni M, Agrawal T, Kheur S. Tooth agenesis: newer concept. J Clin 
Pediatr Dent 2011;36:65-69.

4. Polder BJ, Van't Hof MA, Van der Linden FP, Kuijpers-Jagtman AM. A meta-analysis of the prevalence of dental agenesis of permanent teeth. Community Dent Oral Epidemiol 2004;32:217-226.

5. Punithavathy, John JB, Priya G, Elango I, Stalin. Familial nonsyndromic oligodontia. Contemp Clin Dent 2012;3:S188-S190.

6. He X, Shu W, Kang Y, Li Z, Zhang J, Kari K, et al.. Esthetic and functional rehabilitation of a patient with nonsyndromic oligodontia: a case report from China. J Esthet Restor Dent 2007;19:137-142.

7. Nunn JH, Carter NE, Gillgrass TJ, Hobson RS, Jepson NJ, Meechan JG, et al.. The interdisciplinary management of hypodontia: background and role of paediatric dentistry. Br Dent J 2003;194:245-251.

8. Vastardis H, Karimbux N, Guthua SW, Seidman JG, Seidman CE. A human MSX1 homeodomain missense mutation causes selective tooth agenesis. Nat Genet 1996;13:417-421.

9. Boeira BR, Echeverrigaray S. Novel missense mutation in PAX9 gene associated with familial tooth agenesis. J Oral Pathol Med 2013;42:99105.

10. Lammi L, Arte S, Somer M, Jarvinen H, Lahermo P, Thesleff I, et al.. Mutations in AXIN2 cause familial tooth agenesis and predispose to colorectal cancer. Am J Hum Genet 2004;74:1043-1050.

11. Hobson RS, Carter NE, Gillgrass TJ, Jepson NJ, Meechan JG, Nohl F, et al.. The interdisciplinary management of hypodontia: the relationship between an interdisciplinary team and the general dental practitioner. Br Dent J 2003;194:479-482.

12. Thalji GN, Cooper LF. The role of complete overdentures in esthetic rehabilitation of the adolescent oligodontia patient. A case report. J Esthet Restor Dent 2010;22:213-221.

13. Worsaae N, Jensen BN, Holm B, Holsko J. Treatment of severe hypodontia-oligodontia - an interdisciplinary concept. Int J Oral
Maxillofac Surg 2007;36:473-480.

14. Kirzioglu Z, Koseler Sentut T, Ozay Erturk MS, Karayilmaz H. Clinical features of hypodontia and associated dental anomalies: a retrospective study. Oral Dis 2005;11:399-404.

15. Bural C, Oztas E, Ozturk S, Bayraktar G. Multidisciplinary treatment of non-syndromic oligodontia. Eur J Dent 2012;6:218-226.

16. Locker D, Jokovic A, Prakash $\mathrm{P}$, Tompson B. Oral health-related quality of life of children with oligodontia. Int J Paediatr Dent 2010;20:8-14.

17. Shilpa, Thomas AM, Joshi JL. Idiopathic oligodontia in primary dentition: case report and review of literature. J Clin Pediatr Dent 2007;32:65-67.

18. Artopoulou II, Martin JW, Suchko GD. Prosthodontic rehabilitation of a 10-year-old ectodermal dysplasia patient using provisional implants. Pediatr Dent 2009;31:52-57.

19. Westwood RM, Duncan JM. Implants in adolescents: a literature review and case reports. Int J Oral Maxillofac Implants 1996;11:750-755.

20. Finnema KJ, Raghoebar GM, Meijer HJ, Vissink A. Oral rehabilitation with dental implants in oligodontia patients. Int J Prosthodont 2005;18:203-209.

21. Mankani N, Chowdhary DR, Patil DB, E DN, Madalli DP. Dental implants in children and adolescents: A literature review. J Oral Implantol 2012 [Epub ahead of print. DOI: 10.1563/AAID-JOI-D-11-00186]

22. Bhalla G, Agrawal KK, Chand $P$, Singh $K$, Singh BP, Goel P, et al.. Effect of complete dentures on craniofacial growth of an ectodermal dysplasia patient: a clinical report. J Prosthodont 2013 [Epub ahead of print. DOI: $10.1111 /$ jopr.12026 